\title{
The Relationships between body image, self-esteem, and future consumption behaviors of college students participating in sports
}

\author{
Boo-Gil Seok, Department of Business Administration, Division of Liberal Arts, Halla University, Wonju, \\ 26404, Korea \\ *Hyun-Suk Park, Department of Business Administration, Division of Liberal Arts, Halla University, Wonju, \\ 26404, Korea, gardencityny97@gmail.com \\ ${ }^{*}$ Corresponding author
}

\begin{abstract}
Participation in sports activities help to establish positive body image. Therefore, this study aims to examine the relationships between body image, self-esteem, and future consumption behavior. To this end, college students who have experience in participating in sports activities were chosen and a questionnaire survey was conducted. A total of 280 questionnaires were distributed and 256 submissions were analyzed with frequency analysis, correlation analysis, and regression analysis. The results of this study are as follows: 1) among the sub-factors of body image, body satisfaction and appearance evaluation show statistically positive effects on self-esteem while appearance-oriented attitude does not show statistically significant effect. Second, the three sub-factors of body image do not have significant effects on future consumption behavior. Third, self-esteem has a positive effect on future consumption behavior. The results of this study show that establishing positive body image helps people to enhance their self-esteem and high self-esteem built based on positive body image, which is formed by participating in sports activities, provokes future consumption behavior. Therefore, further research examining the relationships between the variables of this study needs to be conducted and the findings will ultimately contribute to the growth of sports industry.
\end{abstract}

Keywords: Body Image, Appearance-Oriented Attitude, Body Satisfaction, Appearance Evaluation, Future Consumption Behavior

Received: 09.12.2020 $\quad$ Accepted: $14.01 .2021 \quad$ Published: 02.02.2021

\section{INTRODUCTION}

Generally, college students who can be categorized as late-adolescence are likely to form their own selfimage of body and physical appearance throughout the period of their adolescence. Body image refers to a person's perception of physical and aesthetics attractiveness that an individual creates of themselves. Being exposed to the images of celebrities, especially emphasized through mass media and the Internet, they become satisfied or dissatisfied with their own body image by comparing their images with those of celebrities or the ones described as an ideal in the society they belong to.

It has been pointed out that lookism widespread in modern society causes young-aged people to form distorted body image of their own because they are especially vulnerable to peer and cultural/social pressures. When they are dissatisfied with their body image or have poor body image, they are likely to have low-self esteem, anxiety, and even depression. Therefore, it is extremely important to form positive body image and feel satisfied with it.

Participating in sports activities is one of the effective ways to help form a positive body image [1]. Also, it improves psychological well-being, self-respect, and mental health as well as physical health, resulting in improving the quality of life[2]. Furthermore, by establishing a positive body image through participation in sports activities, one can boost self-esteem[3]. Enhancing self-esteem by participating in any kinds of sports activities leads a person to considering him/herself as valuable and important. Having high self-esteem facilitate a person to continue sports activities and it will eventually contribute to flourishing sports industry.

Self-esteem is one's subjective evaluation of their own worth or value that makes him/her have positive or negative attitude toward him/herself[4]. Self-satisfaction is so important a factor that it determines one's attitude and behavior dealing with upcoming situation and problems. In particular, selfesteem is one of the factors affecting future consumption behavior as it is an essential basic motivation of consumption behavior.

Future consumption behavior is the secondary behavior of consumers' that appears after purchasing any product. It is an active behavior that encompasses supporting the product, repurchase, and 
recommendation of the product[5]. Future consumption behavior plays an important role in marketing as it induces continuous participation in sports activities and increase in the number of people who participate in sports activities. Overall, encouraging people to be involved in sports activities brings the improvement of the quality of life and growth of sports industry.

Considering what is mentioned above, it can be assumed that college students who participate in sports activities are more likely establish positive body image of their own and body image will affect their future consumption behavior either directly through high self-esteem enhanced by sports or indirectly as self-esteem plays a role as a mediator. Therefore, this study aims to investigate the relationships between body image, self-esteem, and future consumption behaviors and ultimately contribute to the growth of sports industry.

\section{Methods}

\subsection{Participants}

The population of this research consisted of college students who have experience participating in sports activities and are currently joining sports activities. College students are chosen for this research because they are amid the period that the formation of body image notably occur. The questionnaires were distributed and collected through both online and offline. A total of 256 questionnaires were used for analysis after eliminating 24 submissions with missing values. The detailed description of the study participants are presented in [Table 1].

Table 1 Overview of participants

\begin{tabular}{|c|c|c|c|c|}
\hline Items & & Categories & $\mathbf{N}$ & $\%$ \\
\hline \multirow[t]{2}{*}{ Gender } & & Male & 154 & 60.2 \\
\hline & & Female & 102 & 39.8 \\
\hline \multirow[t]{4}{*}{ Department } & & Humanities and Social Sciences & 106 & 41.4 \\
\hline & & Engineering & 70 & 27.3 \\
\hline & & Arts and Physical Education & 68 & 26.6 \\
\hline & & Etc. & 12 & 4.7 \\
\hline \multirow{4}{*}{ Grade } & & Freshman & 30 & 11.7 \\
\hline & & Sophomore & 88 & 34.4 \\
\hline & & Junior & 75 & 29.3 \\
\hline & & Senior & 63 & 24.6 \\
\hline \multirow{4}{*}{$\begin{array}{l}\text { Frequency } \\
\text { participation } \\
\text { sports }\end{array}$} & of & 1-2 times a week & 121 & 47.3 \\
\hline & in & 3-4 times a week & 83 & 32.4 \\
\hline & & 5-6 times a week & 43 & 16.8 \\
\hline & & Everyday & 9 & 3.5 \\
\hline
\end{tabular}

\subsection{Framework and Hypothesis}

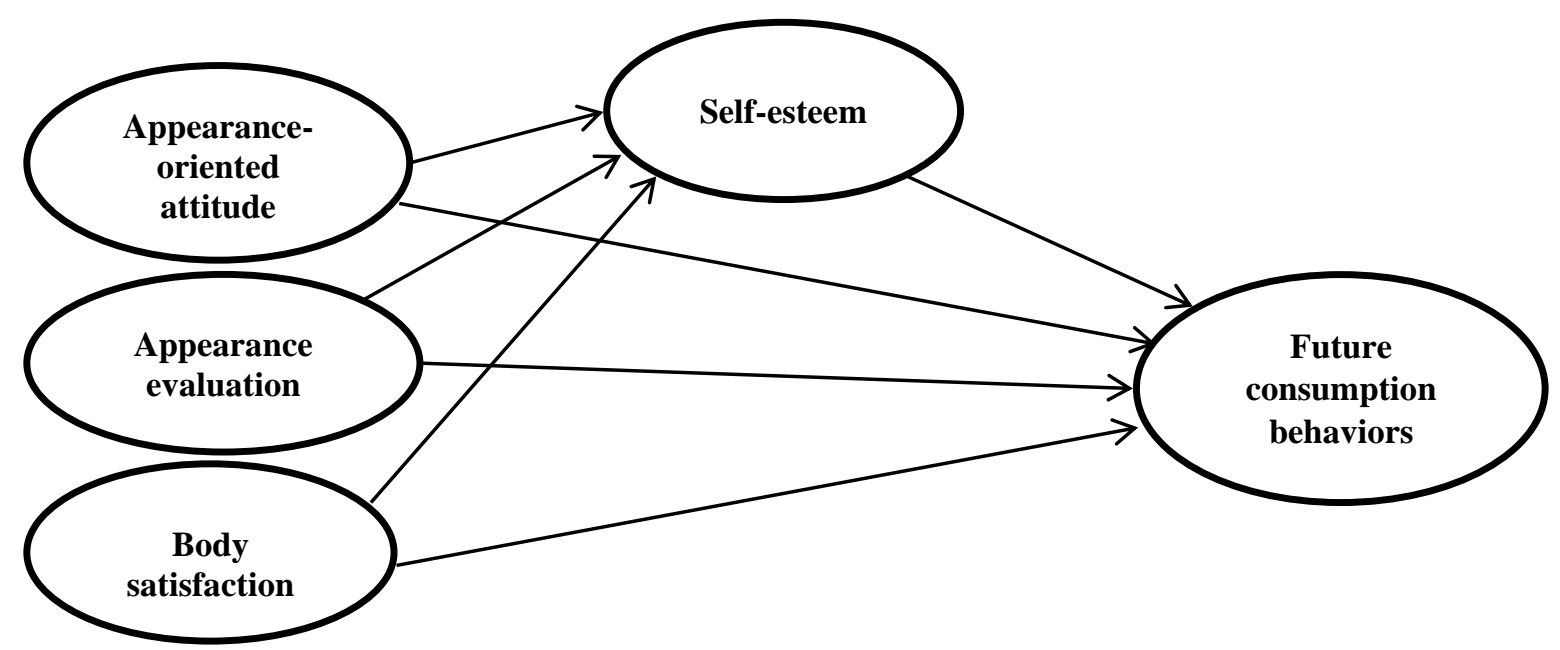

Figure 1 Research model 
H1. Body images of college students participating in sports have a positive effect on self-esteem.

H1-1. Appearance-oriented attitude has a positive effect on self-esteem.

H1-2. Body satisfaction has a positive effect on self-esteem.

H1-3. Appearance evaluation has a positive effect on self-esteem.

H2. Body images of college students participating in sports have a positive effect on future consumption behavior.

H2-1. Appearance-oriented attitude has a positive effect on future consumption behavior.

H2-2. Body satisfaction has a positive effect on future consumption behavior.

H2-3. Appearance evaluation has a positive effect on future consumption behavior.

H3. Self-esteem has a positive effect on future consumption behavior.

\subsection{Instruments}

A self-administered questionnaire was created to collect data on college students' perceptions about their body image, body satisfaction, and future consumption behavior. For body image as an independent variable, a total of 15 question items were used, which were developed in a previous study[5] with a modification to make it more suitable for this study. For self-esteem which was used as a mediating variable, a total of ten question items were included[6]. To measure future consumption behavior, a total of four question items were included[7]. A 5-point Likert scale was used for all the question items to measure three variables.

\subsection{Reliability and Validity of Research Measures}

After a questionnaire being created, two experts in sports tested the content validity of the questionnaire. The construct validity was verified by utilizing the exploratory factor analysis after collecting questionnaires. A principle component analysis was carried out, using a varimax rotation which is used to maximizes the sum of variances of the squared loadings, which indicates correlations between variables and factors. The factors which have eigenvalue of more than one were chosen. Three sub-factors were extracted about body image and the detailed results are presented in [Table 2]. For self-esteem, nine out of ten items fell within one sub-factor. Reliability analysis was conducted, yielding Cronbarch's $\alpha$.839 .904 for body image, and .864 and .883 for self-esteem and future consumption behavior, respectively.

Table 2 Results of exploratory factor analysis for body image

\begin{tabular}{llll}
\hline Factors of body image & 1 & 2 & 3 \\
\hline 1. Appearance-oriented attitude & .882 & .021 & .169 \\
& .880 & .055 & -.033 \\
& .875 & .045 & .078 \\
2. Body satisfaction & .865 & .105 & -.050 \\
& .735 & .047 & .078 \\
& .118 & .869 & .257 \\
& .128 & .852 & .277 \\
3. Appearance evaluation & .058 & .779 & .118 \\
& -.087 & .630 & .377 \\
& .141 & .617 & .497 \\
Total & .058 & .084 & .781 \\
\% of variance & .165 & .242 & .745 \\
Cumulative $\%$ & -.117 & .348 & .693 \\
Cronbarch's $\alpha$ & -.063 & .496 & .679 \\
$\chi^{2}=2534.124, d f=105, p=.000, K M O=.874$ & .248 & .429 & .654 \\
& 5.830 & 3.472 & 1.101 \\
& 38.869 & 23.145 & 7.337 \\
& 38.869 & 62.014 & 69.351 \\
\hline
\end{tabular}

\section{Results and Discussion}

\subsection{The Results of Correlation Analysis}


The correlations between variables were analyzed to find out multicollinearity which explains whether explanatory variables in a multi regression model are highly linearly related. The results indicate that most of the variables have statistically significantly positive correlations, having correlations coefficient less than .08. The results are presented in [Table 3].

Table 3 Correlation analysis

\begin{tabular}{|c|c|c|c|c|c|}
\hline Categories & 1 & 2 & 3 & 4 & 5 \\
\hline 1. Appearance-oriented attitude & 1 & & & & \\
\hline 2. Body satisfaction & $.160^{*}$ & 1 & & & \\
\hline 3. Appearance evaluation & $.148^{*}$ & $.683^{* * *}$ & 1 & & \\
\hline 4. Self-esteem & .041 & $.385^{* * *}$ & $.370^{* * *}$ & 1 & \\
\hline $\begin{array}{l}\text { 5. Future consumption behavior } \\
{ }^{*} p<<.05,{ }^{* *} p<.01,{ }^{* * *} p<.001\end{array}$ & $.151^{*}$ & $.230^{* * *}$ & $.198^{* *}$ & $.474^{* * *}$ & 1 \\
\hline
\end{tabular}

\subsection{The results of hypothesis verification}

To verify the hypothesis of this study, regression analysis was used. The results are as follows: First, multiple regression analysis was conducted to analyze the effect of body image on self-esteem, assigning three sub-factors of body image(appearance-oriented attitude, body satisfaction, and appearance evaluation) as independent variables and self-esteem as a dependent variable $\left(R^{2}=.171, F=17.292^{* * *}\right)$. The results show that among three sub-factors of body image, body satisfaction and appearance evaluation have statistically positive effects on self-esteem $(p<.05, p<.01$, respectively), whereas appearanceoriented attitude does not have a positive effect statistically $(p>.05)$.

Table 4 Hypothesis 1 verification

\begin{tabular}{|c|c|c|c|c|c|}
\hline Variables & $B$ & S.E. & $\beta$ & $t$ & VIF \\
\hline (constant) & 2.464 & .246 & & $10.004^{* * *}$ & \\
\hline Appearance-oriented attitude & -.025 & .049 & -.029 & -.507 & 1.029 \\
\hline Body satisfaction & .238 & .075 & .251 & $3.186^{* *}$ & 1.886 \\
\hline Appearance evaluation & .211 & .081 & .203 & $2.586^{*}$ & 1.878 \\
\hline
\end{tabular}

Second, to find out how body image affects future consumption behavior, the multiple regression analysis was carried out. The results show that among sub-factors of body image, body satisfaction and body evaluation do not have statistically significant effects on future consumption behavior $\left(R^{2}=.069\right.$, , $F=6.198, p>.05$ ).

Table 5 Hypothesis 2 verification

\begin{tabular}{llllll}
\hline Variables & $\boldsymbol{B}$ & $\boldsymbol{S . E}$. & $\boldsymbol{\beta}$ & $\boldsymbol{t}$ & $\boldsymbol{V} \boldsymbol{F}$ \\
\hline (constant) & 3.030 & .261 & & $11.622^{* * *}$ & \\
Appearance-oriented attitude & .096 & .052 & .114 & 1.848 & 1.029 \\
Body satisfaction & .156 & .079 & .165 & 1.974 & 1.886 \\
Appearance evaluation & .071 & .086 & .069 & .827 & 1.878 \\
$R^{2}=.069, F=6.198^{* * *},{ }^{* * *} p<.001$ & & & & & \\
\hline
\end{tabular}

Third, to investigate the effect of self-esteem on future consumption behavior, the simple regression analysis was employed, treating self-esteem as an independent variable and future consumption behavior as a dependent variable. The results show that self-esteem statistically positively affects future consumption behavior $\left(R^{2}=.225, F=73.803, p<.05\right)$.

Table 6 Hypothesis 3 verification

\begin{tabular}{lllll}
\hline Variables & $\boldsymbol{B}$ & $\boldsymbol{S . E}$. & $\boldsymbol{\beta}$ & $\boldsymbol{t}$ \\
\hline (constant) & 2.291 & .214 & & $10.716^{* * *}$ \\
Self-esteem & .474 & .055 & .474 & $8.591^{* * *}$ \\
$R^{2}=.225, F=73.803^{* * *},{ }^{* * *} p<.001$ & & & & \\
\hline
\end{tabular}




\subsection{Discussion}

As physical appearance is inordinately stressed, more and more people concerned about their looks and having negative body image lowers one's self-esteem. However, there has been research that argues one's participation in sports activities actually helps him/her form positive body image and improve their self-esteem[1][2][3]. Therefore, this study tries to examine the relationships between body image, selfesteem, and future consumption behavior and how participation in sports activities helps to establish positive body image and high self-esteem, leading to stimulating future consumption behavior.

The findings of this study tells us that body satisfaction and body evaluation college students have, who are involved in sports activities, positively affect their self-esteem. The results of this study mirrors the previous study that concluded adult women's body image has a positive influence on self-esteem[8]. However, when going into details, the results of this study show as the same results as those of various studies in that body satisfaction positively affects self-esteem[9][10], but considering the relationships between body evaluation and self-esteem, the results of this study are different from a previous study[11]. Targeting different participants may produce different results.

To improve college students' self-esteem, it is necessary to encourage them to satisfy with their body and evaluate their body more positively. That is, supporting them to realize their physical attractiveness and build overall satisfaction with their body is crucial. As these can be achieved through being involved in sports activities[1], it is necessary to encourage students and provide college students with more opportunities to participate in more sports activities. On the other hand, among three sub-factors of body image, appearance-oriented attitude does not have an effect on self-esteem. This result echoes that of previous research[10].

The results of this study also show that body image perceived by college students involved in sports activities does not necessarily affect their future consumption behavior. Therefore, it can be argued that even if a positive body image is established, it does not directly stimulate them to continue sports activities and recommend sports activities to others.

The improvement of self-esteem positively affects future consumption behavior. The results from previous research, which indicate that self-esteem facilitate one's intention of continuing sports activities[11], the improvement of self-esteem satisfies psychological desire[12], and satisfaction achieved from sports activities positively affects recommendation intention[13], prove that self-esteem and future consumption behavior have a causal relationship.

\section{Conclusion}

With the aim to investigate how the perception of one's body image is correlated with self-esteem and future consumption behavior, contribute to improve the quality of life through sports and ultimately the growth of sports industry, this study tries to examine how body image influences self-esteem and future consumption behavior of college students who are involved in sports activities.

The results of this study indicates that body image perceived by college students who join sports activities positively affects their body satisfaction and appearance evaluation, whereas appearanceoriented attitude does not. Also, body image perceived by college students does not have a direct influence on future consumption behavior, while self-esteem positively affects future consumption behavior.

Overall, a positive body image that college students establish about their own body by getting involved in sports activities leads them to satisfying with their body and in turn encourage them to have high selfesteem. Although their positive body image built through participation in sports activities does not directly fuel them to continue sports activities or solicit others for sports activities, it does contribute to improve the quality of their life and activation of sports industry.

Despite meaningful findings, this study is not free from limitations. This study sampled only college students who join sports activities and it can be considered a limitation in terms of the generalizability of the results. Thus, it is suggested that future studies cover various participants in terms of age, socio-status, and so on. In addition, a great deal of research on how participating in sports activities brings positive psychological effect is required.

\section{REFERENCES}

[1] Igbanag JE, Gutin S. Society and the adolescent self-image. Princeton, N. J.: Princeton University Press. 1978.

[2] Cho NK, Oh SY. Review of the importance of leisure participant's affective domain based on attitude, motivation, goal-orientation, self-efficacy, attribution theory. The Korean Journal of Physical Education. 2006:45(3):435-444. Available from: http://kiss.kstudy.com/thesis/thesisview.asp?key=3701785 
[3] Keeton WP, Cash TF, Brown TA. Body image of body image? Comparative multidimensional assessment among college students. Journal of Personality Assessment. 1990:54(2):213-230.

[4] Sonstroem RJ. Exercise and self-esteem. In R. L. Terjung(Ed), Exercise and Sport Science Reviews. Toronto: Collare; 1984. P.132-155.

[5] Cash TF. The multidimensional body-self relations questionnaire. In appendix. Body Image Disturbance, Assessment and Treatment.(Thompson, J. K.), Elmsford, NY: Pergamon Press:1990.

[6] Coopersmith, S. The antecedents of self-esteem. San Francisco, CA: W. H. Freeman \& Co.: 1967.

[7] Brown TJ, Barry TE, Dacin PA, Gunst RF. Spreading the word: Investigating antecedents of consumers' positive word-of-mouth intentions and behaviors in a retailing context. Journal of the Academy of Marketing Science. 2005: 33(2);123-138.

[8] Kwak HP, Koo KJ. (2010). Relationship of leisure dance participation, physical image and self-esteem among women. Journal of the Korea Contents Association. 2010:10(8):407-416. Available from: http://www.dbpia.co.kr/journal/articleDetail?nodeId=NODE01513112

[9] Kang EJ, Kim JS, Lee MY, Lee MK, Oh JS. Official Journal of the Korean Society of Dance Science; 2014:31(1):67-84. Available from: http://kiss.kstudy.com/thesis/thesis-view.asp?key=3232645

[10] Kang PM. The effects of sociability, body image, self-esteem on appearance management behavior. Doctoral dissertation. Chungnam National University: 2017. Available from: http://www.riss.kr/search/detail/DetailView.do?p mat type=be54d9b8bc7cdb09\&control no=d8d d9ab0ad8f1337ffe0bdc3ef48d419

[11] Lee JM. The relationships between class satisfaction, body image, self-esteem and adherence intention of students participated liberal dance class. Korean Journal of Dance. 2019:19(1):1-13. Available from: https://www.dbpia.co.kr/pdf/cpViewer

[12] Lee GC. The effect of basic psychological needs satisfaction on self-esteem of the exercise participants. Journal of the Korea Academia-Industrial cooperation Society. 2016:17(10):490-498. Available from: http://www.dbpia.co.kr/journal/articleDetail?nodeId=NODE07198348

[13] Kim SY, Cho KM, Bae, JS. The effect customer satisfaction regarding boxing club service quality on exercise maintenance and recommendation intention. Korean Journal of Sports Science. 2019:28(1):553-569. Available

from: http://www.dbpia.co.kr/journal/articleDetail?nodeId=NODE07619518 